\title{
Pre operative use of injection diclofenac versus injection tramadol for pain management of acute appendicitis in emergency department
}

\author{
S Giri, S Chaudhuri, S Jirel, BD Aryal, DR Kumar, PP Gupta \\ Department of General Practice and Emergency Medicine \\ B. P. Koirala Institute of Health Sciences, Dharan, Nepal
}

\begin{abstract}
Background: Acute appendicitis is one of the most common causes of acute abdominal pain presenting in emergency department. Preoperative use of adequate analgesia markedly reduces pain without affecting diagnosis accuracy and furthermore no single analgesia has been used for this purpose. Objective: To determine and compare the efficacy of injection diclofenac and injection tramadol for rapid pain management of acute appendicitis in emergency department. Methods: An experimental clinical trial was done including 50 patients aged $\geq 8$ years who were clinically diagnosed as acute appendicitis and had not received analgesia prior to examination by the researcher. They were randomly divided into 2 groups: 25 patients (group 1) were given injection diclofenac intramuscularly and 25 patients (group 2) were given injection tramadol intravenously. Comparative analysis was carried out regarding the decrease in pain intensity using visual analogue scale (VAS) score for pain at presentation, at half an hour and at one hour of drug administration. Results: All the patients had VAS score of $\geq 5$ at presentation without significant difference in the two groups. Half an hour after drug administration, $64 \%$ of subjects still had a VAS score of $\geq 6$ in the first group while only $12 \%$ in the second group $(\mathrm{p}=0.005)$. At one hour of drug administration, $64 \%$ of subjects had a VAS score between 4 and 7 and $36 \%$ had score between 0 and 3 in group 1. In contrast to this score, in group 2 only $16 \%$ of the subjects scored between 4 and 7 and $84 \%$ between 0 and $3(p=0.001)$. Conclusion: There was rapid and marked decrease of VAS score or pain in tramadol group as compared to diclofenac group. Hence, we can recommend that injection tramadol intravenous be considered for preoperative use for pain management of acute appendicitis in emergency department.
\end{abstract}

Keywords: Appendicitis, diclofenac, tramadol

\footnotetext{
Address for correspondence

Saroj Giri, Assistant Professor

Department of GP and EM

B.P. Koirala Institute of Health Sciences, Dharan

Ph. No. 9848029377

E-mail: dr.sarojgiri@gmail.com
} 


\section{Introduction}

Abdominal pain is a common reason for patients presenting to the emergency department. ${ }^{1}$ In acute abdominal pain, for example acute appendicitis, pain is severe. 'For decades, analgesia for acute abdominal pain was withheld until a definitive diagnosis was established for fear of masking the symptoms, changing physical findings or ultimately delaying diagnosis and treatment of a surgical condition. However, early administration of analgesia to such patient can greatly reduce their pain and dose not interfere with a diagnosis, which may even be facilitated due to the severity of physical symptoms being reduced. ${ }^{2}$

Acute appendicitis is the most common cause of an 'acute abdomen in young adults' ${ }^{3}$ It has a lifetime incidence of $7 \%$. The early periumbilical pain in acute appendicitis is due to irritation of surrounding tissues of inflamed appendix. The pain finally gets localized in right iliac fossa with appearance of associated symptoms like anorexia, nausea, vomiting and pyrexia. ${ }^{3}$

The existing literatures identify use of no single analgesia in patient with acute appendicitis, but the studies advocate preoperative use of analgesia for pain management in emergency department. ${ }^{2,5,6}$

Various studies have been done to study the effect of analgesia in acute abdominal pain management and diagnostic accuracy.
However, there is limited literature on the comparison between different analgesics. Most studies have been done on morphine. Double-blind randomized controlled trials and systematic reviews are done on use of analgesia in acute abdominal pain to look their efficacy in relieving pain without impeding the diagnosis. The studies and the reviews provide some evidence to support the notion that the use of opiate analgesics in patients with acute abdominal pain is helpful in terms of patient comfort and does not retard decisions to treat. ${ }^{2,5,7,8,9}$

In Nepal, intramuscular NSAIDs are often used for pre-operative analgesia. However, there are many authors suggesting that intravenous opiates are a good choice. Therefore this study aims to compare the use of intramuscular diclofenac with intravenous opioid analgesia for early pain management of acute appendicitis in the emergency department.

\section{Methods}

This study is a single blind randomized controlled trial conducted in Emergency unit of B.P. Koirala Institute of Health Sciences (BPKIHS), Dharan, Nepal after approval from BPKIHS ethical committee. Fifty patients $\geq 8$ years of age and clinically diagnosed as a case of acute appendicitis willing to participate in the study were included in the study. Patients aged less than 8 years or 
less, who had already received analgesia before seen by the researcher and those who were not suitable for the test drugs were excluded from the study. Written consent was taken from all patients enrolled for the study. They were randomly assigned to group 1 and 2 by simple randomization technique. There was no control group due to ethical issue.A detailed clinical history regarding symptoms (eg. Pain: onset, site, character, radiation etc.) were taken. Physical examination (eg. Pulse, temperature, signs of acute appendicitis etc.) was also done. For the diagnosis of acute appendicitis in the emergency, Alvarado scoring was used.

Patients scoring 7 or more were assumed to have acute appendicitis and were included in the study. ${ }^{23,24,25}$

A visual analog scale (VAS) score was used for evaluating pain. It is based on the principle that 'by 7 to 8 years old, children are usually able to rate their pain on a $0-10$ numeric scale, with $0=$ no pain and $10=$ worst pain that can be imagined'. ${ }^{26}$ The patient was asked to choose a number which they prefer to use to describe their pain best. The pain score was noted thrice: firstly, on admission before they received analgesia; secondly, half an hour after they received analgesia; and, finally, one hour after giving analgesia.

Out of 50 patients included in the study, 25 were administered injection diclofenac (intramuscular) and the other 25 with injection tramadol (intravenous). A standard dose of analgesia was given for all patients over 35 kg body weight: tramadol $50 \mathrm{mg}$; diclofenac $75 \mathrm{mg}$. For patients under $35 \mathrm{~kg}$ in weight, the dose of the drug to be administered was calculated according to the weight of the patient: for tramadol $1 \mathrm{mg} / \mathrm{kg}$; for diclofenac $1.5 \mathrm{mg} / \mathrm{kg}$.

The result (change in VAS before and after receiving analgesia) was recorded.

Statistical analysis was done using SPSS 12.0 software programme. Pearson's chisquare test was performed to compare frequencies in study groups.

\section{Results}

The subjects' ages ranged from 14-55 years. The majority of the subjects were male (64\%). There were no statistically significant differences between the study groups regarding age, gender or weight. The demographic characteristics of the sample. Table- $1 ;(n=$ sample size $=50)$

Table 1: Demographic characteristics of the sample

\begin{tabular}{|l|l|l|}
\hline \multicolumn{1}{|c|}{ Variables } & \multicolumn{2}{c|}{ Drug Group } \\
\hline & $\begin{array}{c}\text { Diclofenac } \\
(\mathrm{n}=25)\end{array}$ & $\begin{array}{c}\text { Tramadol } \\
(\mathrm{n}=25)\end{array}$ \\
\hline 1. Age (Years) & & 13 \\
\hline $11-20$ & 11 & 5 \\
\hline $21-30$ & 12 & 7 \\
\hline$>31$ & 2 & \\
\hline
\end{tabular}




\begin{tabular}{|l|l|l|}
\hline 2. Gender & & \\
\hline Male & 17 & 8 \\
\hline Female & 8 & 10 \\
\hline $\begin{array}{l}\text { 3. Weights } \\
\text { (kgs) }\end{array}$ & & \\
\hline $41-45$ & 5 & 7 \\
\hline $46-50$ & 8 & 6 \\
\hline $51-55$ & 6 & 3 \\
\hline$>56$ & 6 & 9 \\
\hline
\end{tabular}

Table 2: Comparison of Alvarado score

\begin{tabular}{|c|c|c|c|}
\hline & Points & \begin{tabular}{|c|} 
Diclofenac \\
group \\
$(n=25)$
\end{tabular} & $\begin{array}{c}\text { Tramadol } \\
\text { group } \\
(n=25)\end{array}$ \\
\hline \multirow{2}{*}{$\begin{array}{l}\text { Migratory } \\
\text { RIF pain }\end{array}$} & 0 & 7 & 6 \\
\hline & 1 & 18 & 19 \\
\hline \multirow[t]{2}{*}{ Anorexia } & 0 & 3 & 1 \\
\hline & 1 & 22 & 24 \\
\hline \multirow{2}{*}{$\begin{array}{l}\text { Nausea } \\
\text { and } \\
\text { vomiting }\end{array}$} & 0 & 5 & 2 \\
\hline & 1 & 20 & 23 \\
\hline \multirow{2}{*}{$\begin{array}{l}\text { Tendernes } \\
\text { s (RIF) }\end{array}$} & 0 & 0 & 0 \\
\hline & 2 & 25 & 25 \\
\hline \multirow{2}{*}{$\begin{array}{l}\text { Rebound } \\
\text { tenderness }\end{array}$} & 0 & 6 & 6 \\
\hline & 1 & 19 & 19 \\
\hline \multirow{2}{*}{$\begin{array}{l}\text { Elevated } \\
\text { temperature }\end{array}$} & 0 & 0 & 3 \\
\hline & 1 & 25 & 22 \\
\hline \multirow[t]{2}{*}{ Leucocytosis } & 0 & 0 & 0 \\
\hline & 2 & 25 & 25 \\
\hline \multirow[t]{2}{*}{ Shift to left } & 0 & 8 & 4 \\
\hline & 1 & 17 & 21 \\
\hline
\end{tabular}

At presentation in the emergency department, all the patients had either moderate or severe pain. (Fig 1) Among 50 patients, 30 patients $(60 \%)$ had VAS for pain in between 4 and 7. 20 patients (40\%) had a VAS between 8 and 10. The difference between two groups was not significant.

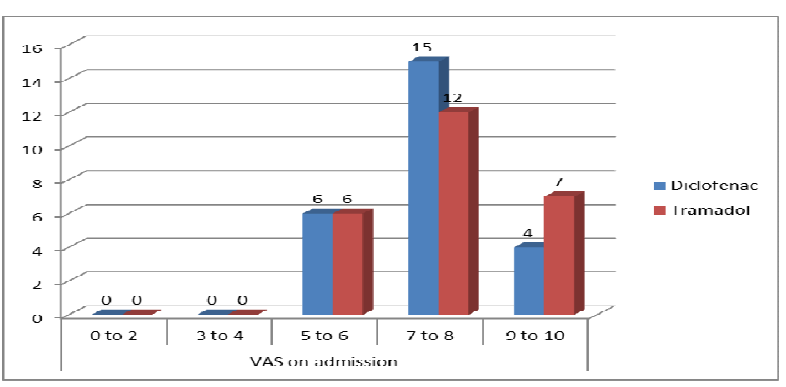

Fig. 1 : Visual analog score on admission

Half an hour after drug administration the VAS was significantly different in the two study groups $(p=0.005)$. In the diclofenac group $64 \%$ of subjects had a VAS of 6 or greater. In the tramadol group the corresponding figure was $12 \%$.

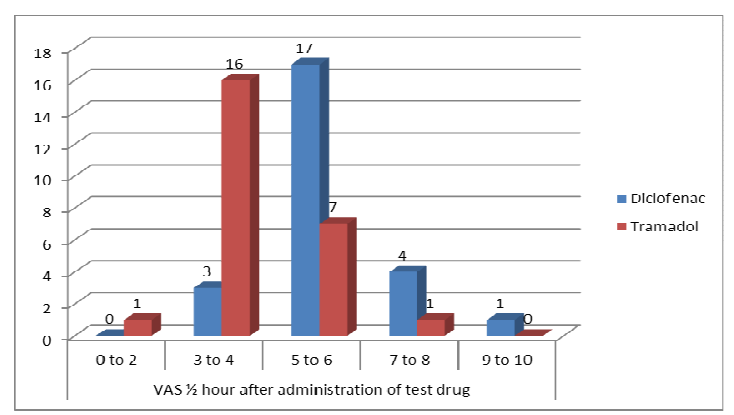

Fig. 2: Visual analog score $1 / 2$ hour after administration of test drug. 
1 hour after administration of the test drug VAS was significantly reduced in both groups, more in the tramadol group. $42 \%$ of the tramadol group scored between 0 and 3, whereas only $18 \%$ of the diclofenac group scored similarly. Only $8 \%$ of the tramadol group scored between 4 and 7, compared with $32 \%$ of the diclofenac group. The difference between groups was highly significant $(p<0.001)$.

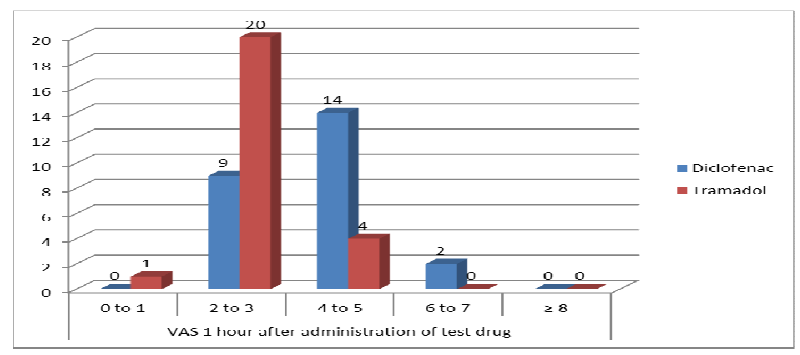

Fig. 3 : Visual analog score 1 hour after administration of test drug.

\section{Discussion}

In this clinical trial, we found that inj. diclofenac and inj. tramadol both were effective in pain control of acute appendicitis. However, it is seen that the effect of injection tramadol was more rapid and peaked within 1 hour of administration. There was a marked decrease in the VAS score even at $1 / 2$ hour after drug administration. In comparison, injection diclofenac reduced the VAS but was slower than injection tramadol. The results attained a high level of significance $(p<0.001)$. The null hypothesis - that there is no difference in effectiveness - is therefore rejected.

This observed difference may be due to the difference in the route of administration of the study drugs rather than the drug characteristics. The serum level of drug following an intravenous injection rises more rapidly than following intramuscular injection. However, diclofenac is not available in a form for intravenous injection and it is a widely used analgesic choice in intramuscular form. This is why a comparison was done using different methods of administration.

The results of this study are consistent with the comprehensive systematic review of 2005 in New Zealand. ${ }^{10}$ This suggested that tramadol would be superior to diclofenac although the only comparative studies at that time used oral formulations. The current study has found the same difference holds when parenteral forms are used.

Our results contrast with that of previous randomized double blind placebo - controlled trial done in Oct. 2007, which showed that morphine at a dose of $0.1 \mathrm{mg} / \mathrm{kg}$ was not effective in pain control at 30 minutes in children with right lower quadrant pain suggestive of appendicitis. This is a reminder that care must be taken in exploiting the results of the current study to opiates as a group and particularly in children. 
Similarly, different prospective randomized controlled studies suggest that NSAIDs are at least as effective as opiates for pain control in patients with acute renal colic, which also do not match with the results of our study. Those studies were done for renal colic where the mechanism of pain is also due to ureteral spasms. NSAIDs have the possible advantage of decreasing ureteral smooth muscle tone. The results of this study should only be applied to the clinical situation of suspected acute appendicitis.

The effectiveness of tramadol in acute abdominal pain has already been seen in various studies but in Nepal it is not so widely used. This can be partly explained by the lack of knowledge of the drug among the health workers of District Hospitals where the patient receives primary care. Anecdotally, there are also fears about the use of opiates among many health workers that make them wary of using such drugs. Fear of drug dependence in patients is an important issue limiting the use of tramadol among health workers who are not medical graduates in the district level. There are also fears about respiratory depression and severe hypotension in the remote health sectors that limit the use of the drug. However, it has been seen that the risks of these adverse effects of tramadol (a synthetic opioid) are minimal or none at all.

Hence adequate knowledge about this synthetic opioid amongst the non medical graduates working in the district level by the supervisor medical superintendents is highly recommended. Furthermore, the traditional use of diclofenac should be reserved for cases where opioids are contraindicated.

Diclofenac has a wider range of potential side effects that can limit its use. The gastric irritation caused by diclofenac and other NSAIDS is well known. $\mathrm{H} 2$ blockers are often given as a routine adjuvant to reduce this side effect. This increases the overall cost of analgesia. Tramadol, on the other hand, requires no H2blocker as this synthetic opioid has relatively no adverse effect on the gastric mucosa. If nausea occurs it can be treated simply and cheaply. Tramadol can usually be used alone without requiring the additional costs of other drugs.

In Nepal, the cost of health care is usually borne solely by the patient. In this low-income setting it is, therefore, particularly important that doctors practice medicine in a costeffective way. Polypharmacy is common and causes an increased financial burden on patients. It has been seen already that the cost effectiveness of tramadol is probably superior to that of diclofenac due to the usage of other adjuvant drugs. Although the cost of a vial of injectable diclofenac is less than the injectable vial of tramadol by just few Nepalese rupees, the adjuvant drug administered along with diclofenac increases its cost effectiveness. 
The VAS proved to be a satisfactory method of assessing analgesic effect. Patients understood the scale and were able to give scores that matched the observed clinical effect. The results were consistent with previous published data. This is further evidence that use of the VAS is a valuable tool in pain studies in a low-literacy setting.

\section{Conclusion}

Injection tramadol has rapid and better efficacy for the pain management of acute appendicitis in emergency setting. We recommend that intravenous tramadol can be considered for use first-line in case of acute appendicitis. There do not appear to be any significant objections to this policy on the basis of safety, efficacy or ease of use.

In order for this method of analgesia to be adopted there would need to be increased understanding of the use of intravenous opiates in pain management. In particular, there could be education about the efficacy, safety profile, cost-effectiveness and ease of use of intravenous tramadol. This should be undertaken in settings such as district hospitals where its use could be anticipated.

Further research could be undertaken comparing different regimes of intravenous analgesia. In particular, a comparison of the use of tramadol and morphine would be instructive. This could address potential fears and concerns about side effects and the duration of analgesic effects.

\section{References}

1. Ranji SR, Goldman E, Simel DL, Shojania KG. Do Opiates affect the clinical evaluation of patients with acute abdominal pain? JAMA.2006;296:176474.

2. Manterola C, Astudillo $\mathrm{P}$, Losada $\mathrm{H}$, Pineda V, Sanhueza A, Vial M. Analgesia in patients with acute abdominal pain. Ann Emerg Med. 2008 Nov; 52(5): 563-6.

3. Russell RCG, Williams NS, Bulstrode CJK. Bailey and Love's short practice of surgery. London. Arnold; 2004: 1201-6.

4. Bromberg R, Goldman RD. Does analgesia mask diagnosis of appendicitis among children? Canadian Family Physician. 2007 Jan. 53(1): 3941.

5. Vermeulen B, Morabia A, Unger PF, Goehring C, G rangier C, Skljarov I, Terrrier F. Accute appendicitis: influence of early pain relief on the accuracy of clinical and US findings in the decision to operate-randomized trial. Radiology. 1999 Mar; 210(3): 63943.

6. Kokki $\mathrm{H}$, Lintula $\mathrm{H}$, Vanamo $\mathrm{K}$, Heiskanen M, Eskelinen M. Oxycodone versus placebo in children with 
undifferentiated abdominal pain; a randomized double-blind clinical trial of the effect of analgesia on diagnostic accuracy. Arch PediatrAdolesce Med. 2005Apr; 159(4): 320-5.

7. Green R, Bulloch B, Kabani A, Hancock BJ, Tenenbein M. Early analgesia for children with acute abdominal pain. Pediatrics 2005;116(4):978-83.

8. Melissa R, Sonya M. Effectiveness of tramadol in acute pain management. Accident compensation corporation version 2.2005.

9. Amoli HA, Golozar A, Keshavorzi, Tavakoli H, Yoghoobi A. Morphine analgesia in patients with acute appendicitis. A randomized double-blind clinical trial. EMJ 2008; 25: 586-9.

10. Aram FO. Preoperative use of analgesia in appendicitis. Saudi Med J. 2008 June; 29(6): 859-62.

11. Bailey B, Bergeron S, Gravel J, Bussieres JF, Bensoussan A. Efficacy and impact of intravenous Morphine before surgical consultation in children with right lower quadrant pain suggestive of appendicitis; a randomised control trial. Ann Emerg Med. 2007 Oct; 50(4): 371-8.

12. Scott LJ, Perry CM. Tramadol: A review of its use in perioperative pain. Codendrugay. 2000; 60(1): 139-76
13. Teichman, JM. Clinical practice: Acute renal colic from ureteral calculus. $\mathrm{N}$ Engl J Med 2004; 350:684.

14. Cordell WH, Wright SW, Wolfson $A B$, Timerding BL, Maneatis TJ, Lewis $\mathrm{RH}$, Bynum L, Nelson DR. Comparison of intravenous ketorolac, meperidine, and both (balanced analgesia) for renal colic. Ann Emerg Med 1996;28(2):1518.

15. Cordell $\mathrm{WH}$, Larson TA, Lingeman JE, Nelson DR, Woods JR, Burns L, Klee LW. Indomethacin suppositories versus intravenously titrated morphine for the treatment of ureteral colic. Ann Emerg Med 1994;23(2):262-9.

16. Uden $\mathrm{P}$, Rentzhog L, Berger T. A comparative study on the analgesic effects of indomethacin and hydromorphinechloride- atropine in acute, ureteral-stone pain. Acta Chir Scand 1983; 149(5): 497-9.

17. Holdgate A, Pollock T. Systematic review of the relative efficacy of nonsteroidal anti-inflammatory drugs and opioids in the treatment of acute renal colic. BMJ 2004 Jun 12;328 (7453):1401. Epub 2004 Jun 3..

18. Klen-Kremer A, Goldman RD. Opoid administration for acute abdominal pain in the pediatric emergency department. J Opioid Manag. 2007; 3(1): 11-4. 
19. Armstrong FD. Analgesia for children with acute abdominal pain: A cutious move to improved pain management. Pediatrics.2005; vol.116, No. 4; 1018-9.

20. Adi KK, Ran DG. Analgesia for children with acute abdominal pain in the emergency department.Israeli Journal of Emergency Medicine. 2006 ; vol.6, no.3: 54-5.

21. Tripathi KD. Essentials of medical pharmacology. New Delhi. Jaypee brothers medical publishers $(\mathrm{P})$ Itd. 2001. 438-62.

22. Katzung BG. Basic and clinical pharmacology, McGraw-Hill companies.2007(10): 506-580.

23. Hong JJ, Cohn SM, Ekeh AP, Newman M, Salama M, Leblang SD, A prospective randomized study of clinical assessment versus computed tomography for the diagnosis of acute appendicitis. Surg Infect (Larchmt). 2003 Fall;4(3):231-9.

24. Denizbasi A, Unluer EE. The role of the emergency medicine resident using the Alvarado score in the diagnosis of acute appendicitis compared with the general surgery resident. Eur $\mathrm{J}$ Emerg Med. 2003;10(4):296-301.

25. Singh K, Gupta S, Pargal P. Application of Alvarado scoring system in diagnosis of acute appendicitis. JK Science 2008; 10:84

26. Murtagh J. Murtagh's General Practice, 4th ed., McGraw-Hill Australia Pty Ltd; 2007:98. 